\title{
Melanin-based colour polymorphism signals aggressive personality in nest and territory defence in the tawny owl (Strix aluco)
}

\author{
Arnaud Da Silva • Valentijn van den Brink • \\ Guillaume Emaresi • Ester Luzio • Pierre Bize • \\ Amélie N. Dreiss • Alexandre Roulin
}

Received: 23 January 2013 /Revised: 15 March 2013 /Accepted: 15 March 2013 /Published online: 5 April 2013

(C) Springer-Verlag Berlin Heidelberg 2013

\begin{abstract}
Nest and territory defence are risky and potentially dangerous behaviours. If the resolution of life history trade-offs differs between individuals, the level of defence may also vary among individuals. Because melanin-based colour traits can be associated with life history strategies, differently coloured individuals may display different nest and territory defence strategies. We investigated this issue in the colour polymorphic tawny owl (Strix aluco) for which plumage varies from dark to light reddish melanic. Accordingly, we found that (1) our presence induced a greater response (flying around) from dark-coloured than light-coloured females and (2) dark reddish males suffered lower nest predation rates than light-coloured males. In experimentally enlarged broods, the probability that females reacted after
\end{abstract}

Communicated by K. McGraw

Arnaud Da Silva and Valentijn van den Brink contributed equally to this work.

A. Da Silva • V. van den Brink · G. Emaresi • E. Luzio • P. Bize •

A. N. Dreiss $\cdot$ A. Roulin $(\square)$

Department of Ecology and Evolution, University of Lausanne,

Biophore Building,

1015 Lausanne, Switzerland

e-mail: alexandre.roulin@unil.ch

\section{A. Da Silva}

Equipe Ecologie Evolutive, UMR CNRS 5561 Biogéosciences, Université de Bourgogne, 6 Boulevard Gabriel,

21000 Dijon, France

Present Address:

A. Da Silva

Behavioural Ecology and Evolutionary Genetics,

Eberhard-Gwinner-Straße,

82319 Seewiesen, Germany we played back the hoot calls of a stranger male was higher if these females were lighter reddish; the opposite pattern was found in experimentally reduced broods with dark parents being more reactive than light parents. Finally, darker females alarmed more frequently when paired with a light than with a dark male, suggesting that partners adjust their behaviour to each other. We also tested whether colouration is used as a signal by conspecifics to adjust the level of their defensive behaviour. Accordingly, breeding females responded more vigorously to a dark than a light reddish stuffed tawny owl placed beside their nest. We conclude that melaninbased colouration is a signal of alternative nest and territory defence behaviour that depends on ecological factors.

Keywords Nest defence · Colour polymorphism ·

Personality $\cdot$ Pheomelanin $\cdot$ Predation

\section{Introduction}

The life history theory proposes that individuals optimally allocate resources among energy-demanding and time-consuming life history traits (Stearns 1992). Some of the best-known life history trade-offs are resource allocation between reproduction and self-maintenance, between offspring number and quality and between current and future reproduction (Stearns 1989). For instance, if past investment in reproduction was made at the expense of self-maintenance, adult survival and the value of current offspring would be reduced (Williams 1966; Roff 1992). A model of aggressiveness towards 
predators revealed that differences in risk-taking behaviour can evolve since individuals with higher future expectations have more to lose and are thus more risk-avoiding (Wolf et al. 2007). Several evolutionary stable strategies to resolve such trade-offs can thus coexist within populations through slight investment differences in current and future reproduction (Wolf et al. 2007).

Investment in current reproduction involves anti-predator behaviour and territory defence against intruders. These activities can increase adult mortality caused by predators and competitors (Montgomerie and Weatherhead 1988) and also increase physiological stress through increased testosterone and corticosterone levels (Marler and Moore 1988; Buchanan et al. 2003; Fontaine et al. 2011), costs that should be lower than the benefits generated by rearing high-quality offspring. Because the cost/benefit ratio of anti-predator and territorial behaviours is likely to differ between individuals (Montgomerie and Weatherhead 1988), individuals may signal to conspecifics prospective investment in these behaviours to settle contests without escalation (Maynard Smith and Parker 1976). Few studies have reported colour traits that signal different reproductive and territorial strategies with compelling evidence mainly restricted to colour polymorphic species (Roulin 2004). For instance, differently coloured individuals were found to adopt alternative reproductive strategies in the white-throated sparrow (Zonotrichia albicollis; Tuttle 2003) and nest defence strategies in the Gouldian finch (Erythrura gouldiae; Mettke-Hofmann 2012).

Melanin-based colouration is an appropriate phenotypic marker of strategies in trade-off resolutions between life history traits. Inherited variation in the deposition of melanin pigments (grey-black eumelanin and reddish brown pheomelanin) is frequently reported to covary with morphology, physiology, life history traits and behaviour such as resistance to stress, sexual activity and aggression (Roulin 2004; Ducrest et al. 2008). Previous studies already reported associations between anti-predator behaviour and melanin-based colouration in a number of species including the common buzzard (Buteo buteo; Boerner and Kruger 2009), marsh harrier (Circus aeruginosus; Sternalski and Bretagnolle 2010), great tit (Parus major; Quesada and Senar 2007), barn owl (Tyto alba; Van den Brink et al. 2012a) and European kestrel (Falco tinnunculus; Van den Brink et al. 2012b). Melanin-based colouration can thus be associated with different levels of aggressiveness and be involved in specific trade-off resolutions such as investment in current and future reproduction.

To study the hypothesis that the degree of melaninbased colouration signals alternative anti-predator and territory defence strategies, we performed a study in the tawny owl (Strix aluco). This owl displays large inter-individual variation in the deposition of melanin pigments that covaries with physiological and life history traits in several European populations (Galeotti and Sacchi 2003; Brommer et al. 2005; Piault et al. 2009; Karell et al. 2011b). Under prime rearing conditions, offspring of dark reddish parents grow faster than those of light reddish parents (Roulin et al. 2004, 2008; Piault et al. 2009), while the opposite pattern is observed when rearing conditions are poor. Thus, under rich conditions, darker reddish individuals may be more aggressive to protect their high-quality offspring than light-coloured ones, whereas under poor conditions, the opposite pattern may prevail. Alternatively, because lighter reddish females skip reproduction more often than darker reddish females (Roulin et al. 2003), when they reproduce, they may have more to lose if their nest is depredated, potentially inducing them to be more aggressive. Therefore, nest defence behaviour in differently coloured parents may be conditional to ecological factors. To investigate how melanin-based colouration covaries with aggressiveness, we performed three types of studies in nests for which the number of nestlings was experimentally manipulated. This manipulation allowed us to investigate whether differently coloured individuals experiencing experimentally reduced or enlarged broods defend their brood differentially. The rationale of this experiment was to generate rich vs. poor environments (i.e. in experimentally reduced vs. enlarged broods), since we have already demonstrated that dark and light reddish tawny owls perform differentially in these contrasted environments (Roulin et al. 2008).

We first began with an analysis of nest defence using a dataset of daylight nest visits collected during 6 years. The tawny owl is well known for its nest defence as it will often attack humans who approach their nest too closely (e.g. Leifert et al. 2004). We examined whether dark or light morphs were more reactive to the presence of researchers. Second, because tawny owls remain territorial during the breeding season, probably because of the risk that intruders kill offspring (e.g. Webster et al. 1999; Birrer and Hüsler 2003), we tested with playback experiments whether differently coloured individuals are differentially prone to evict intruders during the breeding season. During daylight hours, we broadcasted the hoot of a male to examine which of dark or light reddish parents react more often. Third, we performed a playback experiment at night the following year with the extra use of a dark or light reddish stuffed owl placed beside nests. We could thus examine whether a dark or light reddish intruder (i.e. stuffed bird) represents a greater threat to breeding pairs and hence elicits a stronger defensive response. This would indicate that colouration signals the level of aggressiveness to conspecifics. 


\section{Methods}

Study species

The tawny owl is monogamous, philopatric and can live up to 20 years (Galeotti 2001). Clutch sizes vary between one and eight eggs, which hatch between February and the end of May. Males deliver food to their offspring and partner (Sunde 2008; Sasvari et al. 2009), while females distribute the prey items among the progeny. Nestlings leave the nest box even before they are able to fly, at an age of 25-30 days, but parents continue to feed and protect them until they are about 2 months old (Sunde 2008). Because of their 5-10\% larger size and $20-25 \%$ greater body mass (Glutz von Blotzheim 1987), females are also responsible for the majority of nest defence against predators (Wallin 1987), whereas in territorial disputes, males and females are equally active (Sunde and Bølstad 2004). The response to an individual that challenges the territory by singing is most frequent and intense in autumn, when territories are established, and during reproduction (Galeotti 1990; Appleby et al. 1999). Vocalization rate of breeding individuals is higher in sites where floaters are more abundant (Sunde and Bølstad 2004). Thus, territorial disputes are frequent and playback experiments mimic a natural situation. Melaninbased plumage colouration is independent of age and sex and is highly heritable $\left(h^{2}=0.72-0.93\right.$; Brommer et al. 2005; Gasparini et al. 2009; Karell et al. 2011b). Feather content in pheomelanin and eumelanin accounts for 68 and $21 \%$, respectively, in inter-individual variation in the degree of reddish colouration. Feathers of darker reddish individuals contain more pheomelanin and eumelanin (Gasparini et al. 2009).

\section{Study site}

Our study was carried out in a forested area of $911 \mathrm{~km}^{2}$ situated in western Switzerland, at a mean altitude of $672 \mathrm{~m}$ (range, 400-950 m). In this area, 377 nest boxes were set up within forest patches of at least $4,000 \mathrm{~m}^{2}$. The mean distance between two nest boxes was $627 \mathrm{~m}$, with a minimal distance of $500 \mathrm{~m}$ (Roulin et al. 2011); for this reason, a visit at one nest did not disturb neighbouring nests. When nestlings were 10 days of age, breeding females were captured in the nest box during daylight ( 8 a.m. -6 p.m.), while males were captured at night when provisioning their brood (10 p.m. -6 a.m.). We applied the same method to all nests independently of colouration.

\section{Colour measurements}

Male and female breeders were assigned to one of five colour morphs based on the colouration of the entire body
$(1=$ dark reddish brown, $2=$ reddish brown, $3=$ brown, $4=$ brown-grey, 5 =grey; Roulin et al. 2003; Figs. 1 and 2). The scale we used in previous papers is counter-intuitive because darker colouration reflects an increase in melanin pigments in the feathers. To obtain a more logical scale from light to dark reddish, we multiplied the above scale by -1 . Furthermore, the names of the different morphs we coined in 2003 (i.e. brown, grey and reddish) are poorly reflecting that colouration of adult tawny owls show a continuum from dark to light melanic (Gasparini et al. 2009). This is why we now use the terminology light to dark reddish or light to dark melanic. Between-year visual assessments of individual colouration were significantly repeatable in both females (comparing 280 individuals for which morph was determined in different years, $r=0.86 \pm 0.023 \mathrm{SE}, F_{279,613}=11.37, P<0.0001$ ) and males (226 individuals, $r=0.88 \pm 0.025 \mathrm{SE}, F_{225,354}=$ 12.59, $P<0.0001$; Lessels and Boag 1987). We already demonstrated that scores assigned in the field are strongly correlated with colouration measured on back feathers using either Adobe Photoshop or a spectrophotometer (Gasparini et al. 2009).

\section{Brood size manipulation experiment}

Based on the criterion that clutches were laid on similar dates, between 2005 and 2011, we matched 388 out of 545 successfully hatched pairs of nests to reduce (R) or enlarge (E) brood size and in turn induced a decrease and increase in parental investment of breeding pairs, respectively. The average difference in laying dates is 2.8 days (range, 0-9 days); we could sometimes match pairs with more than 1 week difference in laying dates because last-hatched chicks of one brood had similar age as first-hatched chicks of the matched brood. This resulted in a reduced body mass in E parents compared to $\mathrm{R}$ parents (Roulin et al. 2011), demonstrating that the increase in clutch size induces an increase in parental effort. Brood sizes were manipulated by exchanging on average two hatchlings or eggs from a nest $\mathrm{E}$ against three hatchlings or eggs from a nest R. Pairs of nests were randomly selected and colouration of the biological and foster parents were not correlated to each other, neither same sex nor opposite sex (all $P$ values $>0.19$ ). Adult plumage colouration was not associated with clutch size and brood size before or after the manipulation (Spearman's correlations; $P$ values $>0.10$ ). We found no evidence for assortative mating within breeding pairs $\left(r_{\mathrm{s}}=0.05, n=383, P=0.36\right)$. Note that sample sizes can differ between analyses, since we did not always capture both partners. Detailed descriptions of effects of brood size manipulation are reported in Roulin et al. (2011). 
Fig. 1 Differently coloured tawny owls. a Dark reddish brown morph. b Reddish brown morph. c Brown morph. d Brown-grey morph. e Grey morph. Pictures by Guillaume Emaresi
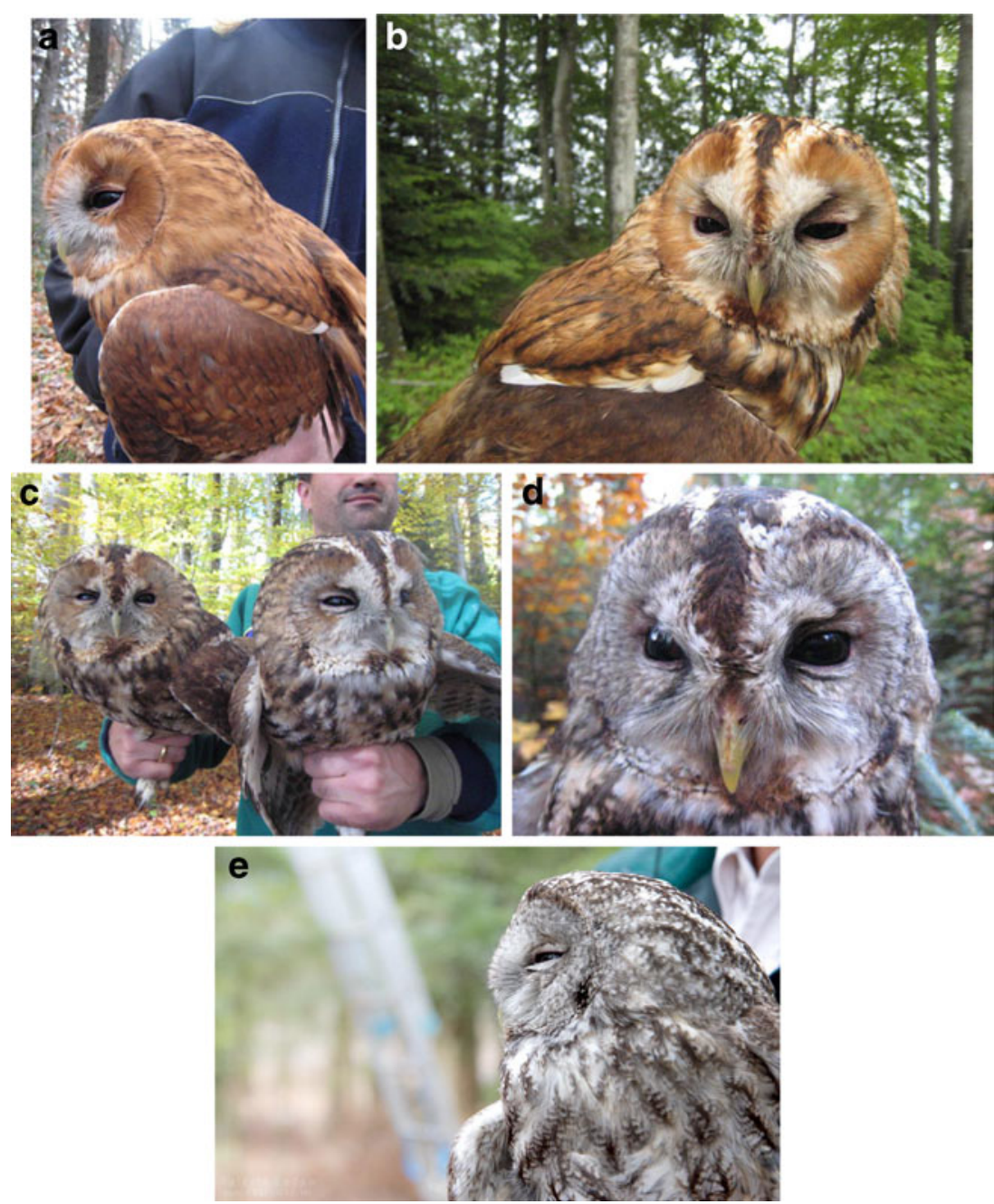

Nest defence during daylight hours in relation to adult colouration

Between 2005 and 2009, we examined whether plumage colouration of the parents was associated with their anti-

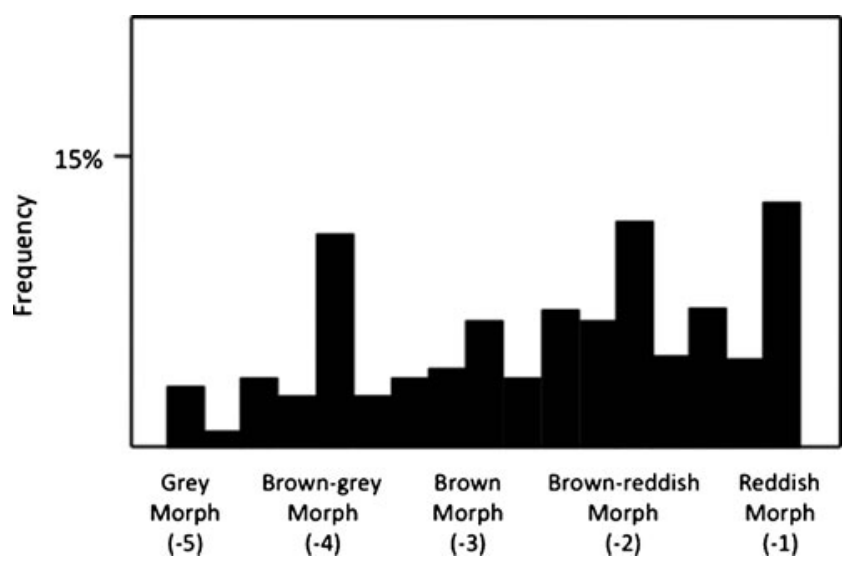

Fig. 2 Frequency distribution of colour morphs of 552 breeding tawny owls predator behaviour. We always parked our car at approximately $30 \mathrm{~m}$ from the nest box, took a ladder from the roof of the car and immediately walked towards the nest box. We climbed the tree, removed the nestlings, ringed and measured them and finally placed them back in their nest box and left. The entire procedure took approximately $30 \mathrm{~min}$ and was independent of bird colouration, and during this time period, we observed whether parents were visible in the surroundings. We considered 1,555 brood visits performed in 318 nests during daylight hours when nestlings were old enough to be thermo-independent (mean $\pm \mathrm{SE}=20.2 \pm$ 0.2 days of age). At this time, parents do not roost in the nest anymore (Glutz von Blotzheim 1987) but usually in a tree nearby to detect any potential predator. During these daylight visits, adults were often detected thanks to alerting passerines. We determined sex either visually based on sexual size dimorphism (Baudvin and Dessolin 1992) or the type of alarm calls (Galeotti and Pavan 1991). When we did see an adult that was sitting still in a tree (or when we did not see it at all and did not hear any passerines alerting), we considered them as not adopting any anti-predator 
behaviour. But when we saw an adult flying around us, vocalising or attacking us, we considered it as adopting an anti-predator behaviour. Nest defence behaviour is very conspicuous and hence cannot be missed. For this reason, the probability to detect an owl that defends its nest is not influenced by its colouration. Age of the adults was determined upon capture by ring numbers or moult patterns (Baker 1993). Birds were assigned to the age categories 'yearling' or 'adult'.

We used a generalized linear mixed model (GLMM) with a logit link function and parental anti-predator behaviour as a binomial response variable. We incorporated female identity and year as two random factors to account for individuals breeding in more than 1 year (only 20 out of 212 females were only seen breeding in 1 year) and for more than one visit to the same nest in the same year (mean number of visits per nest, $4.0 \pm$ 0.08 ; range, 1-9). Independent variables were female colour morph, female age, brood size manipulation treatment (i.e. experimentally enlarged and reduced broods), time of the day (mean, $1405 \mathrm{~h} \pm 35 \mathrm{~min}$; range, 6-21 h), date (i.e. number of days after 1 January; range, 4 February-24 June), nestling age and initial brood size before manipulation (mean, $3.9 \pm 0.04$; range, 1-7 nestlings). In a preliminary model, we incorporated two-way interactions between female colouration and the other independent variables. We performed a similar model for breeding males. We had a sample of 163 experimentally enlarged nests, 160 experimentally reduced broods and 85 non-manipulated broods. We first ran an analysis by considering only experimental nests and then confirmed the results by using the entire sample of nests.

Nest predation in relation to adult colouration

Between 2005 and 2010, we recorded breeding success or failure. It is difficult to distinguish predation from abandonment in the egg phase and, therefore, we limited our analysis to the nestling phase. We had a sample of 165 experimentally enlarged broods, 163 experimentally reduced broods and 106 non-manipulated nests to examine the relationship between nest predation and parental colouration. We considered a nest as depredated (most often by mustelids) when the nestlings were missing long before they should have fledged at 25-30 days or when we found them dead with injuries. To investigate possible differences in predation risk between parents of different colour, we performed a GLMM with a logit link function and presence/absence of predation on nestlings as binomial response variable. We included year, brood identity and identity of the mother and father as four random variables. Independent variables were adult colouration, sex and age of the adults, brood size manipulation treatment and all two-way interactions. Unfortunately, we could not test whether predation was more frequent in pairs, showing no anti-predator behaviour during daylight hours because we usually noticed that a nest was depredated when the mother should still have been roosting in her nest. We confirmed the results using all 434 nests regardless of whether we manipulated brood size.

Playback experiment during daylight hours in 2010

In 2010, we studied 26 experimentally enlarged and 26 reduced broods of similar mean hatching date (Student's $t$ test, $t_{50}=1.11, P=0.27$ ). Between 21 April and 18 May, when nestlings were $29 \pm 0.8$ SE days old, we performed a playback experiment during daylight hours (mean, $1201 \mathrm{~h} \pm$ $12 \mathrm{~min}$; range, $0850-1550 \mathrm{~h}$ ). In all nests, we captured the parents a couple of days before performing the playback experiment. Male and female colouration was not significantly associated with time of the day, date and offspring age at the time of the playback (Spearman's correlations, $P$ values $>0.31$ ); including these variables in preliminary statistical analyses did not modify our results. We placed a stereo $\mathrm{CD}$ player at $10 \mathrm{~m}$ from the nest box and played territorial calls of a male tawny owl during $5 \mathrm{~min}$. We chose this duration because a previous study showed that $50 \%$ of the birds already respond to a playback within $5 \mathrm{~min}$, while it could take up to $20 \mathrm{~min}$ for more than $90 \%$ of the birds to respond (Redpath 1994). We could thus test which of dark and light reddish parents respond rapidly to a playback. This soundtrack was a series of three hoots per minute from a male originating from a breeding population in the UK, unknown to all owls in our local population. Note that tawny owls respond more strongly to the hooting of stranger males than to the hooting of known neighbouring males (Galeotti and Pavan 1993). During the playback, we retreated to approximately $20 \mathrm{~m}$ from the nest, visually recording tawny owl presence or absence as well as whether passerines produced alarm calls. The latter measure is an efficient proxy of movement of tawny owls that otherwise remain hidden to avoid being mobbed by passerines (Hogstad 1995); more than 20 years of experience showed us that passerines are producing alarm calls when an owl is moving. During our playback experiment, we saw or heard an owl on 18 occasions out of 52 occasions and we heard passerines on 24 occasions. We ran a first series of logistic regression models with presence or absence of at least an owl (i.e. heard and/or seen) during our playback experiment as a binomial response. In the second series, the binomial response was either presence or absence of a reaction from the owls (i.e. heard and/or seen) or passerines (i.e. alarming or not). In these two models, we included brood size manipulation treatment and colour morph of the two parents, as well as all two-way interactions. 
Playback experiment at night in 2011

Between 19 April and 23 May 2011, we performed a playback experiment in 13 experimentally enlarged broods and 18 experimentally reduced broods when nestlings were $17.6 \pm 0.4$ days old and a second time when they were $21.1 \pm 0.4$ days old. Eight nest boxes that were occupied in 2010 were also used in 2011, five by the same pair, two by the same female and one by the same male. We performed the playback experiment at night (mean time, $2315 \mathrm{~h} \pm 12 \mathrm{~min}$; range, 2115-0115 h) because we expected owls to be more active at this time. We placed a recorder (Marantz PMD 661) and microphone (Beyerdynamic MC 930) at $10 \mathrm{~m}$ from the front of the nest box and then retreated to a location at $10 \mathrm{~m}$ away. We used the same male tawny owl territorial call as used the year before to perform playback experiments. A loudspeaker was placed on the ground close to the nest box, and after $3 \mathrm{~min}$ of silence as an acclimation period, we played back twice in a row a sequence of $8 \mathrm{~min}(3 \mathrm{~min}$ of calls followed by $5 \mathrm{~min}$ of silence). To test whether colour morph of an intruder influences the response of the territory owner, we presented next to the loudspeaker a stuffed owl of either dark or light reddish morph. It was covered under a black sheet until we broadcasted calls. We assigned the dark and light reddish stuffed owl independently of the colouration of the two breeding adults (Wilcoxon tests, males: $z=1.77, P=0.08$; females: $z=-0.38, P=0.71$ ).

As a measure of the response to our playback, we counted the number of female alarm calls ('wick'; Galeotti 2001). On 35 occasions, we heard at least 1 alarm call; on 9 occasions, the female was present (she produced contact calls directed to males, 'kewick'; Galeotti 2001) but did not produce any alarm call; and on 18 occasions, we neither heard nor saw the female. When we heard no alarm call, we assigned a zero to the number of alarm calls. To examine whether the response to the playback experiment was associated with colouration of the territory owner, we introduced log-transformed call rate as an dependent variable in linear mixed models; female identity and replicate (the playback experiment was performed on two separate nights always with the same stuffed owl) were two random variables, and colour morph of the territory owner and of the stuffed owl as well as brood size manipulation treatment were three fixed effects. We performed the playback experiments on two nights to determine whether individual females responded similarly to our playback on different nights.

\section{Statistical procedure}

All analyses were performed using JMP 9.0.2 (SAS 2010) and SAS v9.1 (SAS 2008). GLMM were performed with SAS, whereas logistic regressions (without any random variables) were carried out with JMP. Final models were obtained by eliminating non-significant variables, nonsignificant interactions first. All tests were two-tailed and $P$ values smaller than 0.05 are considered significant; values are reported as means \pm standard error.

\section{Results}

Nest defence during daylight hours in relation to adult colouration

Female tawny owls were more often seen during our daylight visits (1,039 observations, $66.8 \%$ of our visits) than males (357 times, $23.0 \%$ of visits). Females were more likely to adopt an anti-predator behaviour when they were dark rather than light reddish (GLMM with female identity and year as random variables; estimate, $0.28 \pm 0.11 ; F_{1,918}=$ $6.57, P=0.011)$, when they reared an experimentally enlarged rather than reduced brood $\left(0.46 \pm 0.23, F_{1,918}=5.60\right.$, $P=0.018)$ and when their offspring were older $(0.08 \pm 0.01$, $\left.F_{1,918}=29.21, P<0.0001\right)$. In an initial model, the variables time of the day, date, clutch size, female and male age, male colouration and two-way interactions with brood size manipulation experiment and other independent variables were not significant $(P$ values $>0.38)$ and hence removed from the final model. When considering also nests independently of whether we manipulated brood size or not, we still found a significant effect of female colouration on antipredator behaviour (GLMM; estimates, $0.31 \pm 0.11 ; F_{1,1274}=$ $8.01, P=0.0047)$. The random factor 'female identity' had a significant effect as shown by the log-likelihood ratio test $\left(\chi^{2}=173.35, P<0.0001\right)$, indicating that females behaved consistently across nest visits. The random factor 'year' was also significant $\left(\chi^{2}=697.1, P<0.0001\right)$, but the interaction between year and female colouration was not significant in a model where year was included as a fixed cofactor $\left(F_{5,1303}=0.68, P=0.64\right)$.

In a similar analysis, males were more likely to adopt an anti-predator behaviour in the afternoon rather than morning (GLMM with male identity and year as random variables; estimate, $\left.0.10 \pm 0.03 ; F_{1,825}=124.18, P<0.0001\right)$, when the offspring were younger $\left(-0.17 \pm 0.02, F_{1,825}=106.19, P<\right.$ $0.0001)$ and tended to do so when brood size was experimentally reduced compared to enlarged $\left(-0.71 \pm 0.32, F_{1,825}=\right.$ $3.51, P=0.06$ ). The other independent variables (male and female colouration, male and female age, clutch size and date) and two-way interactions were not significant $(P>0.17)$. We obtained similar results when considering all nests independently of whether we manipulated brood size or not (not shown). In contrast to females, the random factor "male identity' had no significant effect (log-likelihood ratio test, $\chi^{2}=0.01, P=0.92$ ), indicating that males did not behave consistently across nest visits. The random factor 'year' 
was also significant $\left(\chi^{2}=731.51, P<0.0001\right)$, but the interaction between year and male colouration was not significant in a model where year was included as a fixed cofactor $\left(F_{5,505}=0.40, P=0.81\right)$.

Nest predation in relation to adult colouration

Nine of the 165 experimentally enlarged broods were depredated at the nestling age $(5.5 \%)$ compared to 18 of the 163 experimentally reduced broods $(11.1 \%)$. Nest predation was lower at nests of darker-coloured than lighter-coloured males (GLMM with male and female identities as well as year as three random variables; estimate, $-0.51 \pm 0.24 ; F_{1,42}=$ 4.44, $P=0.041$; Fig. 3 ); the other terms (brood size manipulation, female colouration, male and female age and all twoway interactions) were not significant and hence removed from the final model. When considering also nests that were not manipulated (7 of 106 were depredated), the association between male colouration and predation was still significant (estimate, $-0.48 \pm 0.24 ; F_{1,59}=4.04, P=0.049$ ). The random effect year was significant $\left(\chi^{2}=90.63, P<0.0001\right)$, which was not the case for the identity of male and female $\left(\chi^{2}<0.02, P>0.9\right)$.

Playback experiment during daylight hours in 2010

The probability that we saw or heard an owl when we played back the hoot of a male tawny owl was significantly associated with colour morph of the two parents in interaction with the brood size manipulation experiment (logistic regression analysis, male colour morph [chi-square test]: $\chi^{2}=1.32, P=0.25$; female colour morph: $\chi^{2}=0.52, P=0.47$; brood size manipulation: $\chi^{2}=0.01, P=0.92$; interaction brood size manipulation $\times$ male colour morph: $\chi^{2}=9.13, P=0.0025$;

\section{Dark reddish}

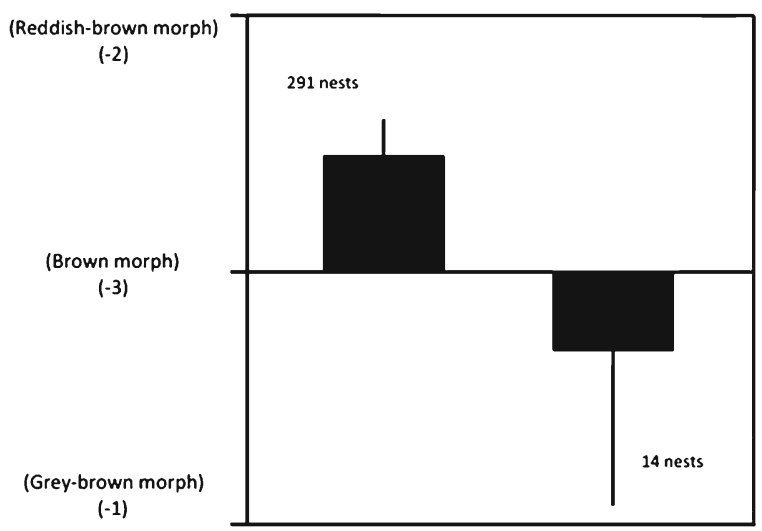

Light reddish

No predation

Predation

Fig. 3 Mean \pm SE colouration of male tawny owls in relation to whether their brood had been depredated or not interaction brood size manipulation $\times$ female colour morph: $\left.\chi^{2}=5.13, P=0.024\right)$. The significant interaction is explained by the fact that, when rearing an enlarged brood, adult owls were more often seen or heard when the male or the female were lighter reddish (male: $\chi^{2}=7.47$, $P=0.006$, estimate $=-1.54 \pm 0.76$; female: $\chi^{2}=3.75$, $P=0.05$, estimate $=-0.97 \pm 0.59$; Fig. $4 \mathrm{a}$ ), while in the reduced treatment, adult colouration did not differ regardless of whether we saw an adult owl (male: $\chi^{2}=2.12, P=0.15$; female: $\chi^{2}=1.50, P=0.22$; Fig. $4 \mathrm{a}$ ). When the binomial response was bird reaction (i.e. adult owl and/or passerines), the only significant term was the interaction between brood size manipulation and female colour morph $\left(\chi^{2}=13.02, P=0.0003\right)$. In the reduced treatment, we observed a bird reaction (i.e. adult owl and/or alarming passerines) more often when the female was darker reddish (female colour morph: $\chi^{2}=10.78, P=0.0010$, estimate $=1.69 \pm 0.71$; male colour morph: $\chi^{2}=0.63, P=0.43$ ), while in the enlarged treatment, we observed the opposite pattern with more frequent bird reaction when the female was lighter coloured (female colour morph: $\chi^{2}=3.78$, $P=0.05$, estimate $=-0.70 \pm 0.40$; male colour morph: $\chi^{2}=0.75$, $P=0.39$; Fig. 4b).

\section{Playback experiment at night in 2011}

Females responded more often than males ( 71 vs. $27 \%$, chisquare test: $\left.\chi^{2}=21.8, P<0.001\right)$. Females tended to produce a similar number of alarm calls in the two successive nights both for when we were sure that females were around their nest (repeatability $=0.28 \pm 0.09, F_{26,27}=1.77, P=0.07$ ) and did so when considering all nests regardless of whether females were proved to be around their nest or not (repeatability $=0.52 \pm 0.09, F_{15,25}=2.73, P=0.024$ ).

In a linear mixed model, the log-transformed number of female alarm calls was higher when the stuffed owl was darker rather than lighter reddish (nest and replicate as two random variables, $F_{1,31.62}=5.81, P=0.022$; Fig. 5), but was not significantly associated with female colouration $\left(F_{1,26.44}=0.44, P=\right.$ $0.52)$ and the brood size manipulation experiment $\left(F_{1,28.03}=\right.$ 3.20, $P=0.085)$; all interactions between colour of the adult stuffed owl and breeding female were not significant $(P>0.40)$. When considering only cases where the female was proved to be around her nest, we obtained similar results (colour of the stuffed owl: $F_{1,26.95}=3.74, P=0.06$; female colour: $F_{1,23.63}=$ $0.26, P=0.61$; brood size manipulation: $F_{1,24.6}=0.70, P=0.41$ ).

In another linear mixed model, we analysed the logtransformed number of female alarm calls in relation to colouration of both the female and male partners and found a significant interaction (nest and replicate as two random variables; female colour: $F_{1,25.63}=10.23, P=0.0037$; male colour: $F_{1,25.77}=4.66, P=0.04$; interaction: $F_{1,25.65}=9.48$, $P=0.0049$ ). To examine this interaction, we split males into 
Fig. 4 Colouration of the two tawny owl parents that reacted to a male hoot broadcasted during daylight hours in 2010 for both when they reared an experimentally reduced or enlarged brood. a Colouration of the two parents when we saw (or did not see) any adult during the playback experiment. b We consider the situation where we saw at least one parent owl or heard alarming passerines during the playback experiment or when we did neither see any tawny owl parent nor heard passerines. Means are given with bars indicating SD a

\section{Dark reddish}

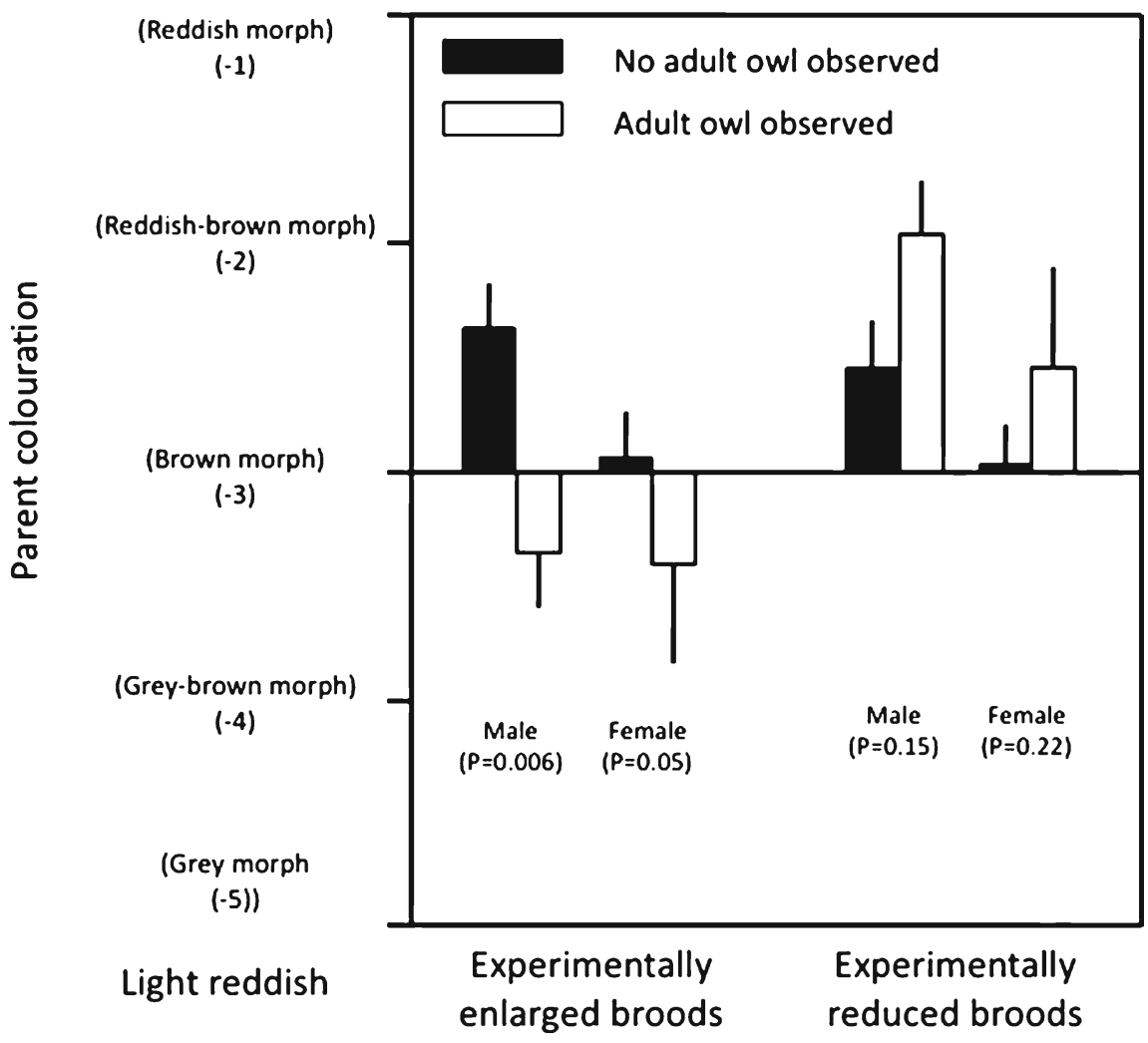

b Dark reddish

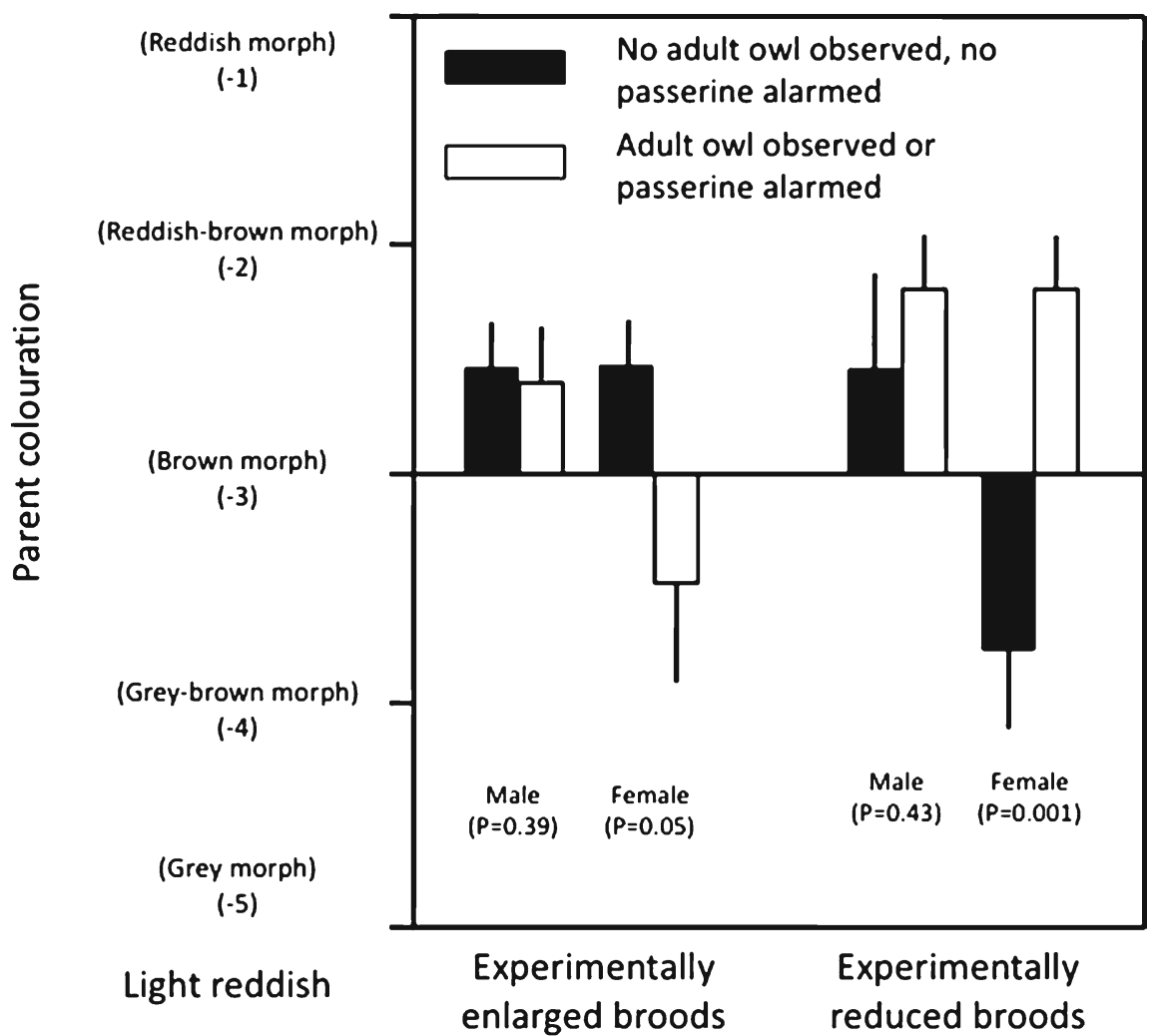




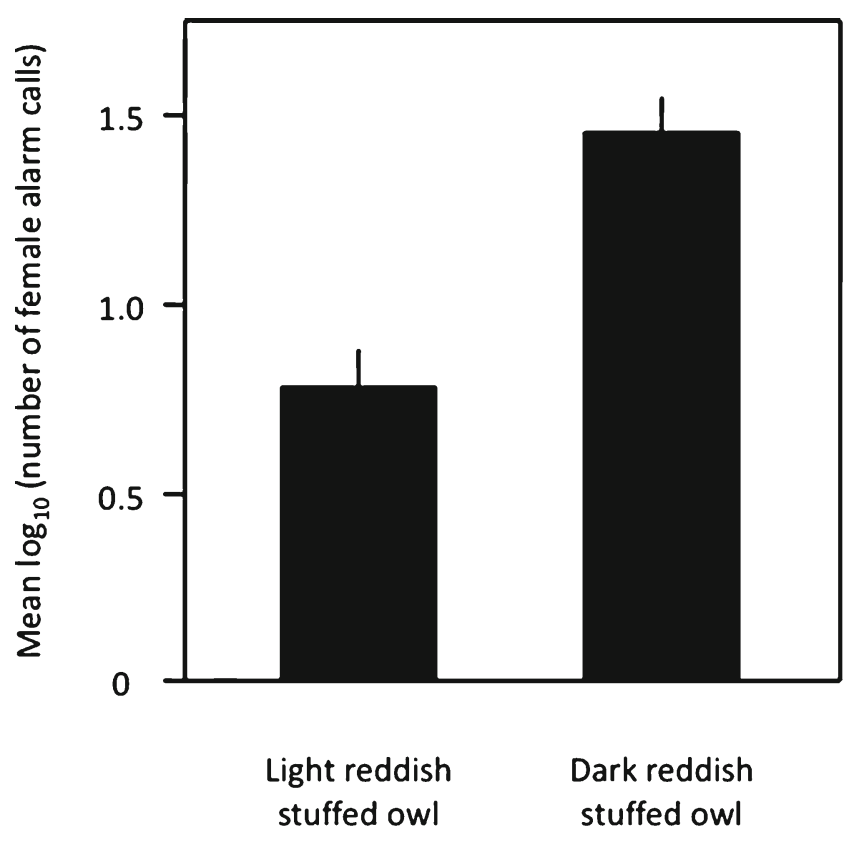

Fig. 5 Number of alarm calls by breeding females in the presence of a stuffed dark or light reddish tawny owl placed beside their nest. Data from 2011

two categories based on the median of their colour distribution, resulting in a group of dark-coloured males and a group of light-coloured males. Then, for each nest, we calculated the mean number of female alarm calls measured in the two nights. Females paired with males assigned to the category 'light coloured' produced more alarm calls when these females were darker reddish $(r=0.67, n=14$ nests, $P=$ 0.009 ); in contrast, we found no significant relationship between the number of female alarm calls and female colouration for females paired with males assigned to the category 'dark' ( $r=0.14, n=16$ nests, $P=0.62)$ (Fig. 6).

\section{Discussion}

Our nest visits during daylight hours mimicked the presence of a potential predator. These visits induced dark reddish female tawny owls more often than light reddish females to move from their hide and be aggressive towards us. Further tests showed that, when we experimentally enlarged broods, lighter-coloured parents reacted more often after we played back the hoot of a stranger male than darker parents. Interestingly, the opposite pattern was detected in experimentally reduced broods where darker females were more reactive. When the playback was carried out at night, we observed that females alarmed more often when we placed a dark than light reddish stuffed owl near their nest. In the same experiment, we also found that dark reddish females alarmed more frequently when paired with a light rather than a dark male. Finally, predation at the nestling stage was more frequent when the father was light rather than dark reddish. We, therefore, conclude that melanin-based colouration is associated with anti-predator and territorial behaviour during the reproductive season and also that conspecifics may assess colouration to adjust their behaviour in front of another individual.

\section{Sex-specific investment in nest defence}

Nest defence can be costly and risky, particularly in terms of survival and injuries (Wallin 1987). In owls and raptors,
Fig. 6 Number of alarm calls by breeding females in relation to their own colouration and colouration of their partner. Data from 2011. For birds captured on several occasions and for which we assigned a different score, we calculated a mean score value

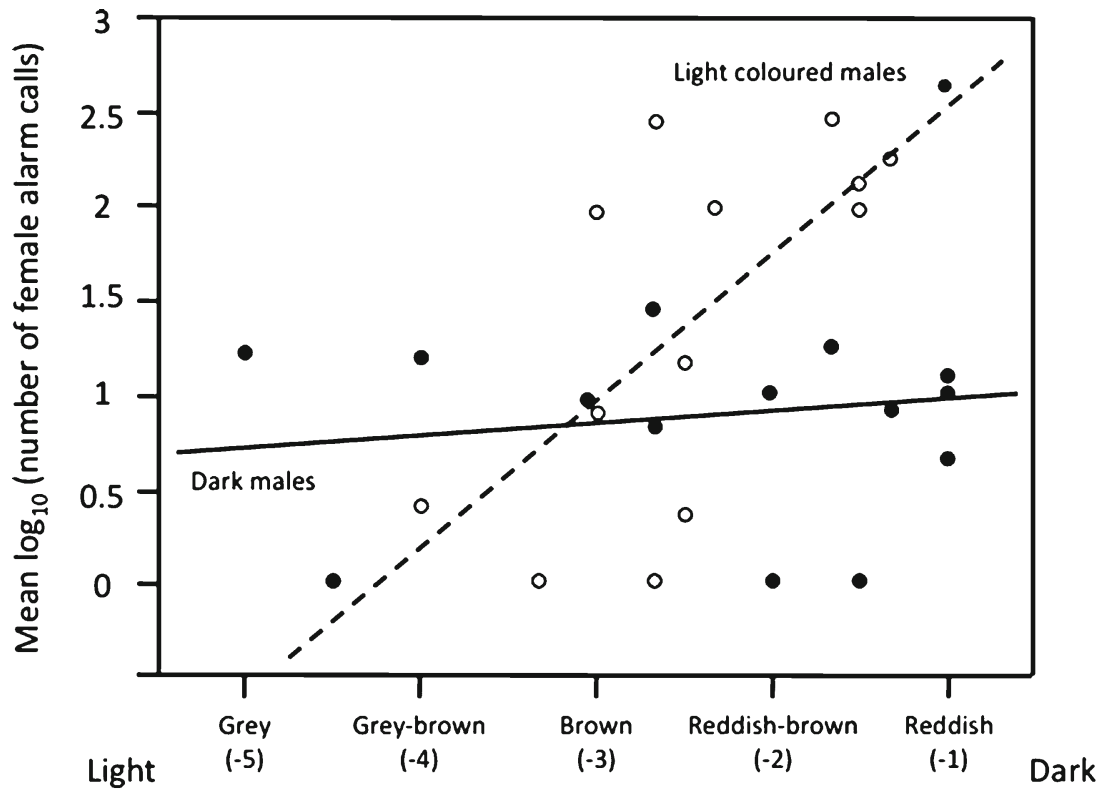

Female colour morph 
selection often favoured females to be larger and heavier than males, leading them to be more intensively involved in protecting the offspring than males that are mostly involved in hunting for the progeny (Wiklund and Stigh 1983). Accordingly, our daily visits to tawny owl nests induced females to fly around us 2.9 times more often than males, and the playback experiments induced more intense nest defence by females than males. Interestingly, while females adopted an anti-predator behaviour mainly when their offspring were older, males did so mainly when their offspring were younger. This sex-specific temporal pattern of nest defence could be explained by the sex-specific roles in reproduction (Galeotti 2001). When offspring are still young, the mother is dedicated to feeding and warming them and hence she may count on the male to defend the nest. When the offspring are older and hence their food requirement increases, males have to spend more time hunting, while the mother does not need to stay in her nest to warm and feed their offspring anymore. At that stage, she has, therefore, more time to defend the nest. We also observed that females are more likely to defend their nest in experimentally enlarged rather than reduced broods, while the males tended to defend more often experimentally reduced than enlarged broods. This is again consistent with sex-specific roles in reproduction, since males have to spend more time hunting for enlarged than reduced broods. This implies that males can invest more effort in nest defence for reduced than enlarged broods, while females may have to compensate for reduced male effort in this activity in experimentally enlarged broods.

\section{Dark reddish owls are commonly more aggressive}

A major goal of our study was to test whether colour morphs differentially defend their nest against predators and intruders as shown in a number of related species (see the "Introduction" section). As expected, melanin-based colouration was associated with anti-predator behaviour and in turn with reproductive success, but in a rather complex way. We found associations between colouration and indexes of nest defence more often in the sex that invests more effort in this activity, i.e. female. Most of our results suggest that darker reddish females are more aggressive than lighter conspecifics: during our daylight nest visits, we saw more often dark than light reddish females: darker reddish females reacted more strongly to the playback experiments performed during daytime (when brood size was experimentally reduced or when their partner was lighter reddish), and finally at night, a dark-coloured stuffed owl placed beside their nest induced a stronger reaction of females than a lightcoloured stuffed owl. The latter result suggests further that dark reddish owls represent a greater threat than lightly coloured conspecifics. In males, we also found that broods were less often depredated when the father was dark rather than light reddish. Altogether, our findings suggest that dark and light reddish tawny owls evolved alternative life history strategies (Brommer et al. 2005; Roulin et al. 2008; Karell et al. 2011b) that necessitate different physiology (Galeotti and Sacchi 2003; Gasparini et al. 2009; Piault et al. 2009: Karell et al. 2011a) and behaviour (present study). Determining how dark and light reddish birds achieve the same fitness (e.g. one morph may survive longer but produce smaller broods than the other morph) and identifying the selective mechanism behind the evolutionary stability of this polymorphism (e.g. frequency-dependent selection or local adaptation) are major challenges. Because inter-individual variation in the degree of reddish colouration is explained almost solely by genetic factors (Brommer et al. 2005; Gasparini et al. 2009; Karell et al. 2011b), the evolutionary stability of several morphs within populations implies that they should achieve the same fitness. Therefore, the observation of directional selection favouring one morph may be only a transient situation. In one study, Brommer et al. (2005) found that light-coloured individuals had a fitness advantage, whereas in another study performed in the same country (but at a larger scale), they found the opposite result with dark reddish owls being favoured (Karell et al. 2011b). In this context, the present study has the merit to reveal that behaviour is an important component to understand how colour polymorphism is maintained.

Darker reddish tawny owls were more aggressive either towards conspecifics or predators, and hence, if plumage colouration acts as a signal, we would predict that differently coloured individuals induce different behaviours from conspecifics. For a first test, we presented a stuffed owl beside active nests to examine whether darker reddish stuffed individuals induce stronger defensive behaviour from territory owners than lighter reddish individuals. This was the case, as already observed in the buzzard in a similar experiment (Boerner and Kruger 2009). Therefore, plumage colouration may be used as a mate choice criterion, something that remains to be tested. Because the costs and benefits of aggressiveness may vary between years and environments, the most reddish owls may not necessarily be the most preferred mates in all situations and by all individuals, which may explain why pairing with respect to colouration is not assortative in our study and also in Finland (Brommer et al. 2005). Indeed, a light colouration may signal other qualities than aggressiveness. Colour may act as a signal not only in the context of mate choice but also to resolve conflicts over territory ownership. The tawny owl is territorial throughout the year, competing for limited reproductive sites, with high-quality holes in trees being usually rare. Thus, colouration may be a signal of agonistic behaviour, like the black badges in the siskin (Carduelis spinus; Senar and Camerino 1998), house sparrow (Passer 
domesticus; Møller 1987; Klvanova et al. 2011), Gouldian finch (E. gouldiae; Pryke and Griffith 2009) and great tit (Quesada and Senar 2007). If colouration has a major function in defending territories, light reddish owls may be relegated to the poorest-quality territories, something that remains to be formally tested.

Why are light reddish owls aggressive in some situations?

In 2010 and 2011, we found contrasting results with respect to the association between colouration and response to the playback. In 2010, when broods were experimentally enlarged, males and females were more reactive if light coloured. In contrast, when broods were experimentally reduced, darker females were more reactive to the playback. These results are consistent with previous findings showing that offspring sired by darker parents perform better under good conditions, i.e. when brood size is experimentally reduced (Roulin et al. 2008) or when food is abundant (Piault et al. 2009), whereas offspring sired by light parents grow faster under poor conditions, i.e. when food supply is low (Piault et al. 2009). These relationships were found between offspring raised by foster parents and colouration of their biological parents, suggesting a genetic link between colour and the ability to grow fast under contrasting environmental conditions. Therefore, darker parents may invest in nest defence mainly when their offspring are reared in prime conditions compared to lighter parents from the same population. In 2011, food supply was very low and, as a consequence, reproductive success was low which could explain why, regardless of male coloration, female response to the playback experiment was not associated with female colouration. This may explain why dark females were more aggressive when paired with a light than dark male. In this situation, females probably had to compensate for the low level of male aggressiveness in front of an intruder.

Acknowledgments We thank Wolf Harmening for his advice and Rory Hambling (UK) for providing us with the sample of the hooting male owl. The study was financed by the Swiss National Science Foundation to AR (grant no. 31003A_120517). We are grateful to the three reviewers who provided useful comments on an earlier version of the text.

Ethical standards The study was carried out with the authorization of the 'Service Vétérinaire du canton de Vaud'.

\section{References}

Appleby BM, Yamaguchi N, Johnson PJ, MacDonald DW (1999) Sexspecific territorial responses in tawny owls Strix aluco. IBIS 141:91-99

Baker K (1993) Identification guide to European non-passerines. British Trust for Ornithology Guide 24. British Trust for Ornithology, Norfolk
Baudvin H, Dessolin L (1992) Analyse de la morphometrie de la chouette hulotte (Strix aluco) en Bourgogne. Alauda 60:3-104

Birrer S, Hüsler M (2003) Ein Fall von Infantizid bei der Schleiereule Tyto alba. Ornithol Beob 100:143-146

Boerner M, Kruger O (2009) Aggression and fitness differences between plumage morphs in the common buzzard (Buteo buteo). Behav Ecol 20:180-185

Brommer JE, Ahola K, Karstinen T (2005) The colour of fitness: plumage coloration and lifetime reproductive success in the tawny owl. Proc R Soc Lond B 272:935-940

Buchanan KL, Evans MR, Goldsmith AR (2003) Testosterone, dominance signalling and immunosuppression in the house sparrow, Passer domesticus. Behav Ecol Sociobiol 55:50-59

Ducrest AL, Keller L, Roulin A (2008) Pleiotropy in the melanocortin system, coloration and behavioral syndromes. Trends Ecol Evol 23:502-510

Fontaine JJ, Arriero E, Schwabl H, Martin TE (2011) Predation and circulating corticosterone levels within and among species. Condor 113:825-833

Galeotti P (1990) Territorial behaviour and habitat selection in an urban population of the tawny owl Strix aluco L. Bull Zool 57:59-66

Galeotti P, Pavan G (1991) Individual recognition of male tawny owls (Strix aluco) using spectrograms of their territorial calls. Ethol Ecol Evol 3:113-126

Galeotti P, Pavan G (1993) Differential responses of territorial tawny owls Strix aluco to the hooting of neighbours and strangers. IBIS 135:300-304

Galeotti P (2001) Strix aluco tawny owl. BWP Update 3:43-77

Galeotti P, Sacchi R (2003) Differential parasitaemia in the tawny owl (Strix aluco): effects of colour morph and habitat. J Zool 261:9199

Gasparini J, Bize P, Piault R, Wakamatsu K, Blount JD, Ducrest AL, Roulin A (2009) Strength and cost of an induced immune response are associated with a heritable melanin-based colour trait in female tawny owls. J Anim Ecol 78:608-616

Glutz von Blotzheim UN (1987) Handbuch der Vögel Mitteleuropas. Aula-Verlag, Wiesbaden

Hogstad O (1995) Alarm calling by willow tits, Parus montanus, as mate investment. Anim Behav 49:221-225

Karell P, Ahola K, Karstinen T, Kolunen H, Siitari H, Brommer JE (2011a) Blood parasites mediate morph-specific maintenance costs in a colour polymorphic wild bird. J Evol Biol 24:1783-1792

Karell P, Ahola K, Karstinen T, Valkama J, Brommer JE (2011b) Climate change drives microevolution in a wild bird. Nat Commmun 2:208

Klvanova A, Horakova D, Exnerova A (2011) Nest defence intensity in house sparrows Passer domesticus in relation to parental quality and brood value. Acta Ornithol 46:47-54

Leifert D, Haefliger IO, Pruente C (2004) Imitation of typical birdcall causes ocular perforation by a tawny owl attack. Arch OphthalmolChic 122:1556-1557

Lessels CM, Boag PT (1987) Unrepeatable repeatabilities: a common mistake. Auk 104:116-121

Marler CA, Moore MC (1988) Evolutionary costs of aggression revealed by testosterone manipulations in free-living male lizards. Behav Ecol Sociobiol 23:21-26

Maynard Smith J, Parker GA (1976) The logic of asymmetric contests. Anim Behav 24:159-175

Mettke-Hofmann C (2012) Head colour and age relate to personality traits in Gouldian finches. Ethology 118:906-916

Møller AP (1987) Variation in badge size in male house sparrows Passer domesticus - evidence for status signaling. Anim Behav 35:1637-1644

Montgomerie RD, Weatherhead PJ (1988) Risks and rewards of nest defence by parent birds. Q Rev Biol 63:167-187 
Piault R, Gasparini J, Bize P, Jenni-Eiermann S, Roulin A (2009) Pheomelanin-based coloration and the ability to cope with variation in food supply and parasitism. Am Nat 174:548-556

Pryke SR, Griffith SC (2009) Socially mediated trade-offs between aggression and parental effort in competing color morphs. Am Nat 174:455-464

Quesada J, Senar JC (2007) The role of melanin- and carotenoid-based plumage coloration in nest defence in the Great Tit. Ethology 113:640-647

Redpath SM (1994) Censusing tawny owls Strix aluco by the use of imitation calls. Bird Study 41:192-198

Roff DA (1992) The evolution of life-histories - theory and analysis. Chapmann and Hall, New York

Roulin A (2004) The evolution, maintenance and adaptive function of genetic colour polymorphism in birds. Biol Rev 79:815-848

Roulin A, Bize P, Ravussin P, Broch L (2004) Genetic and environmental effects on the covariation between colour polymorphism and a life-history trait. Evol Ecol Res 6:1253-1260

Roulin A, Ducret B, Ravussin P, Altwegg R (2003) Female colour polymorphism covaries with reproductive strategies in the tawny owl Strix aluco. J Avian Biol 34:393-401

Roulin A, Emaresi G, Bize P, Gasparini J, Piault R, Ducrest AL (2011) Pale and dark reddish melanic tawny owls differentially regulate the level of blood circulating POMC prohormone in relation to environmental conditions. Oecologia 166:913-921

Roulin A, Gasparini J, Bize P, Ritschard M, Richner H (2008) Melanin-based colorations signal strategies to cope with poor and rich environments. Behav Ecol Sociobiol 62:507-519

SAS (2008) SAS 9.1, 91st edn. SAS, Carey

SAS (2010) JMP 9.02, 902nd edn. SAS, Carey

Sasvari L, Peczely P, Hegyi Z (2009) Plasma testosterone profile of male tawny owls Strix aluco in relation to breeding density, breeding experience, and offspring provision. Acta Ornithol 44:59-68

Senar JC, Camerino M (1998) Status signalling and the ability to recognize dominants: an experiment with siskins (Carduelis spi$n u s)$. Proc R Soc Lond B 265:1515-1520
Stearns SC (1989) Trade-offs in life-history evolution. Funct Ecol 3:259-268

Stearns SC (1992) The evolution of life histories. Oxford University Press, Oxford

Sternalski A, Bretagnolle V (2010) Experimental evidence of specialised phenotypic roles in a mobbing raptor. Behav Ecol Sociobiol 64:1351-1361

Sunde P (2008) Parent-offspring conflict over duration of parental care and its consequences in tawny owls Strix aluco. J Avian Biol 39:242-246

Sunde P, Bølstad MS (2004) A telemetry study of the social organization of a tawny owl (Strix aluco) population. J Zool $263: 65-76$

Tuttle EM (2003) Alternative reproductive strategies in the whitethroated sparrow: behavioral and genetic evidence. Behav Ecol 14:425-432

van den Brink V, Dolivo V, Falourd X, Dreiss AN, Roulin A (2012a) Melanic color-dependent antipredator behavior strategies in barn owl nestlings. Behav Ecol 23:473-480

van den Brink V, Henry I, Roulin A (2012b) Docility covaries with a eumelanin plumage trait in juvenile kestrels (Falco tinnunculus). Ethology 18:673-682

Wallin K (1987) Defense as parental care in tawny owls (Strix aluco). Behaviour 102:213-230

Webster A, Cooke R, Jameson G, Wallis R (1999) Diet, roosts and breeding of powerful owls Ninox strenua in a disturbed, urban environment: a case for cannibalism? Or a case of infanticide? EMU 99:80-83

Wiklund CG, Stigh J (1983) Nest defense and evolution of reversed sexual size dimorphism in snowy owls Nyctea scandiaca. Ornis Scand 14:58-62

Williams GC (1966) Natural selection costs of reproduction and a refinement of Lack's principle. Am Nat 100:687-690

Wolf M, Van Doorn GS, Leimar O, Weissing FJ (2007) Life-history trade-offs favour the evolution of animal personalities. Nature 447:581-584 